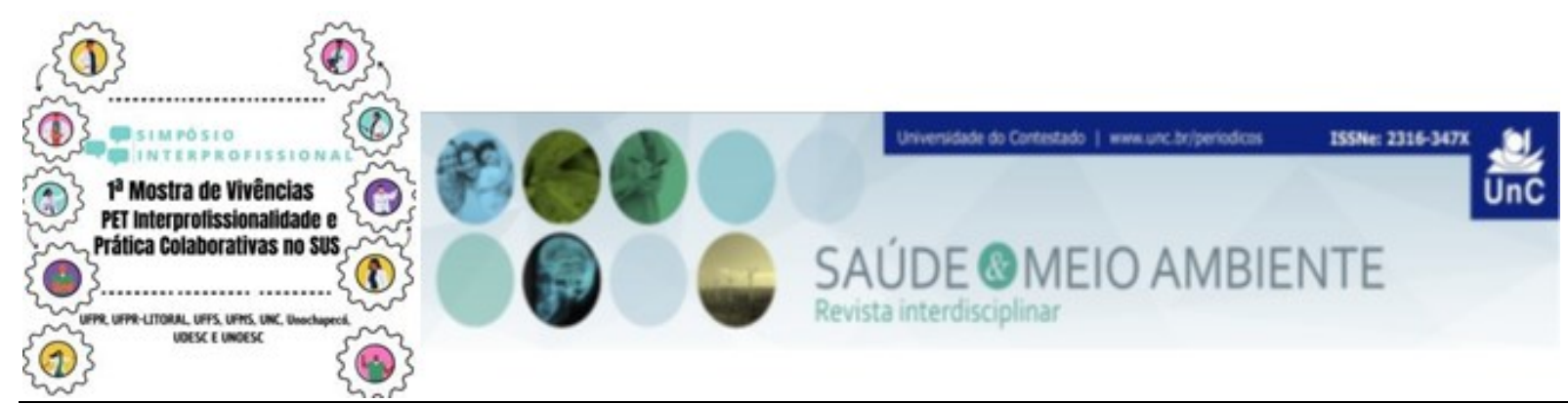

\title{
O PROCESSO DE IMPLANTAÇÃO DO MAPA INTELIGENTE VIRTUAL NO TERRITÓRIO DE ABRANGÊNCIA NO CENTRO DE SAÚDE DA FAMÍLIA EFAPI, SITUADO NO MUNICÍPIO DE CHAPECÓ-SC: UM RELATO DE EXPERIÊNCIA ${ }^{1}$
}

\author{
Projeto 139
}

\author{
Sabrina Mara Martiori² \\ Laura Carolina Kepler ${ }^{3}$ \\ Analú Frozza 4 \\ Bernardo da Veiga Dalben ${ }^{5}$ \\ Geile Fistarol $^{6}$ \\ Lilian Marin Lunelli ${ }^{7}$ \\ Altamir Trevisan Dutra ${ }^{8}$ \\ Suzana Ines Berlt $^{9}$
}

\section{RESUMO}

Introdução: A gestão em saúde, de forma participativa, pode ser realizada por meio da confecção de mapas para identificação das necessidades de saúde da comunidade. Neste contexto, o mapa inteligente virtual - (MIV) é uma estratégia criativa que possibilita planejar e compreender o território de forma mais eficiente. Objetivo: Reconhecer o território de abrangência do Centro de Saúde da Família (CSF) - EFAPI, através da confecção de um MIV. Metodologia: Este estudo trata-se de um relato de experiência da confecção de um MIV, realizado pelo grupo PET Interprofissionalidade. A confecção do MIV foi realizada no período de maio e junho de 2019. O grupo manteve contato as Agentes Comunitárias de Saúde (ACS), e a população, realizando reconhecimento do território. A coleta dos dados realizou-se no sistema eletrônico próprio da Secretaria Municipal de Saúde de Chapecó - WinSaúde e a confecção do mapa pela plataforma google maps, registrando em tempo real as informações que foram disponibilizadas pelas equipes do CSF. Resultados: As informações que constaram no MIV retrataram o perfil epidemiológico da comunidade como: número de pacientes com comorbidades crônicas (hipertensos, diabéticos e acamados), número de crianças menores de 2 anos, gestantes, áreas de

\footnotetext{
1 Fonte de financiamento: Programa de Educação pelo Trabalho para a Saúde - PET Saúde/Interprofissionalidade 2019-2021 (Edital no 10 de 23 de julho de 2018, Ministério da Saúde/Secretaria de Gestão do Trabalho e da Educação na Saúde).

${ }^{2}$ Acadêmica bolsista. Unochapecó. Santa Catarina. Brasil. E-mail: sabrina.m@unochapeco.edu.br

${ }^{3}$ Acadêmica bolsista. Unochapecó. Santa Catarina. Brasil. E-mail: laura.kepler@unochapeco.edu.br

${ }^{4}$ Acadêmica bolsista. Unochapecó. Santa Catarina. Brasil. E-mail: analu.f@unochapeco.edu.br

${ }^{5}$ Acadêmico bolsista. Unochapecó. Santa Catarina. Brasil. E-mail: dalben@unochapeco.edu.br

${ }^{6}$ Preceptora bolsista. Unochapecó. Santa Catarina. Brasil. E-mail: geilef@unochapeco.edu.br

${ }^{7}$ Coordenadora bolsista. Unochapecó. Santa Catarina. Brasil. E-mail: fisiolilian@unochapeco.edu.br

${ }^{8}$ Tutor bolsista. Unochapecó. Santa Catarina. Brasil. E-mail: miridutra@unochapeco.edu.br

9Preceptora bolsista. Unochapecó. Santa Catarina. Brasil. E-mail: suzana.berlt@gmail.com
} 
vulnerabilidade social, focos de mosquito da dengue, locais como escolas e centros comunitários localizados no território. Considerações Finais: A produção do MIV proporcionou exercitar o trabalho efetivo em grupo através de estratégias de territorialização em saúde e obter uma visão holística e humanitária da comunidade. Ao final da confecção do MIV os estudantes destacaram a disponibilidade e a qualidade do trabalho das ACS, auxiliando e organizando as micro áreas para potencializar a prevenção e promoção da saúde. Além de desenvolver estratégias de intervenção voltadas ao auxílio da população junto ao CSF e ainda poder oferecer maior atenção a população com às suas particularidades. Como existe variação nos dados das condições e necessidades de saúde, é importante que o MIV seja atualizado constantemente, assim possibilitará gerar relatórios de saúde ou levantamentos do comportamento populacional de saúde com dados mais precisos.

Palavras-chave: Centro de Saúde. Gestão em Saúde. Agentes Comunitárias da Saúde.

\section{REFERÊNCIAS}

1. Ribeiro MA, Albuquerque IMN, Diniz JL, Bezerra AKB, Bastos IB. Oficina Mapa Vivo na atenção básica: estratégia de planejamento local ao combate ao Aedes aegypti. Saúde debate [Internet]. 2017 jun [citado 2020 jul 29]; 41 (spe2): 338-346. Disponível em: http://www.scielo.br/scielo.php?script=sci_arttext\&pid=S010311042017000600338\&lng=pt. https://doi.org/10.1590/0103-11042017s228 